\title{
Hydrotropic Pulping of Miscanthus to Obtain Pulp
}

Igor N. Pavlov*a, Alexey A. Kukhlenko ${ }^{a}$ and Yulia V. Sevastyanova ${ }^{b}$ ${ }^{a}$ Institute for Problems of Chemical and Energetic Technologies of the SB RAS 1 Sotsialisticheskaya Str., Biysk, 659322, Russia

${ }^{b}$ Northern (Arctic) Federal University named after M.V. Lomonosov

17 Nab. Severnoy Dviny, Arkhangelsk, 163002 Russia

Received 28.06.2019, received in revised form 18.08.2019, accepted 12.11.2019

The hydrotropic pulping of crushed straw of Miscanthus sacchariflorus Andersson to produce pulp was studied herein. A concentrated sodium benzoate solution was used as the reagent. Established regularities of the pulping temperature and time effects on delignification quality attributes such as pulp yield and residual lignin content in the pulp. The generalized arithmetic-mean optimization parameter enabled hydrotropic pulping optimum conditions to be identified to obtain hard pulp fit. Experimentally displayed the possibility of using cellulose for the manufacture of special paper grades.

Keywords: Miscanthus sacchariflorus Andersson, hydrotropic pulping, delignification, cellulose, paper specimens, optimization parameter.

Citation: Pavlov I.N., Kukhlenko A.A., Sevastyanova Yu.V. Hydrotropic pulping of Miscanthus to obtain pulp, J. Sib. Fed. Univ. Chem., 2019, 12(4), 483-493. DOI: 10.17516/1998-2836-0144.

(c) Siberian Federal University. All rights reserved

* Corresponding author E-mail address: pawlow-in@mail.ru 


\title{
Гидротропная варка мискантуса
}

\section{для получения целлюлозы}

\author{
И.Н. Павлова ${ }^{\mathbf{a}}$ А.А. Кухленко ${ }^{\text {, Ю.В. Севастьянова }}$ \\ ${ }^{a}$ Институт проблем химико-энергетических технологий СО РАН \\ Россия, 659322, Бийск, ул. Социилистическая, 1 \\ ${ }^{6}$ Северный (Арктический) федеральный университет \\ им. М.В. Ломоносова \\ Россия, 163002, Архангельск, наб. Северной Двинь, 17
}

Проведены исследования гидротропной варки измельченной соломы мискантуса Miscanthus sacchariflorus Andersson с целью выделения целлюлозы. В качестве реагента использован концентрированный раствор бензоата натрия. Установлены закономерности влияния температуры и продолжительности варки на показатели качества делигнификачии выход целлюлозы и содержание в ней остаточного лигнина. На основе обобщенного среднеарифметического параметра оптимизачии установлены оптимальные условия проведения гидротропной варки для получения жесткой целлюлозы. Экспериментально показана возможность использования целлюлозы для изготовления особых сортов бумаги.

Ключевые слова: мискантус Miscanthus sacchariflorus Andersson, гидротропная варка, делигнификаиия, иеллюлоза, образиы бумаги, параметр оптимизаџии.

\section{Введение}

В целлюлозно-бумажной промышленности многие десятилетия в качестве основного сырья выступали древесные сырьевые материалы. Интенсивное их использование для производства целлюлозы и бумаги создало огромный дефицит запасов древесины [1-3]. Значительное увеличение спроса на бумагу на фоне нехватки времени для воспроизведения древесного сырья привело к применению недревесного сырья для изготовления бумаги различных сортов. В качестве источников бумажной массы предложено использовать волокна практически любых недревесных растений (однолетние растения, сельскохозяйственное сырье, быстрорастущие растения) [4-7]. Самым перспективным среди них является быстрорастущее растение рода Miscanthus Andersson: Miscanthus sacchariflorus, Miscanthus sinensis, Miscanthus purpurascens, а также Miscanthus x giganteus [8-11]. Растущий интерес и увеличивающиеся объемы возделывания позволяют применять его для производства бумаги и картона [12-15].

Традиционны в технологии производства для извлечения целлюлозы крафт-сульфитные процессы, которые вредны для окружающей среды. Альтернативными способами служат методы извлечения целлюлозы из недревесных видов сырья с помощью щелочной экстракции, органических растворителей, обработки ультразвуком [16-20]. Применение технологии гидротропной варки рассматривается как перспективная альтернатива наиболее применяемым технологиям предобработки разбавленной кислотой и щелочной обработки, поскольку направлено на разработку конкурентоспособной и экономически жизнеспособной технологии. 
В настоящей работе рассмотрено применение метода гидротропной варки для выделения целлюлозы, пригодной для использования в производстве бумажных изделий. Известно, что целлюлоза из недревесного сырья, полученная гидротропным способом, характеризуется повышенным содержанием нецеллюлозных компонентов, которые в сумме могут составлять до $15 \%$ с высоким содержанием остаточного лигнина [21]. В то же время для технической целлюлозы, используемой в производстве бумажных изделий, важно сохранение гемицеллюлоз, содержащихся в исходном сырье [22-24], так как гемицеллюлозы способствуют повышению механической прочности, улучшают проклейку и размалываемость целлюлозы. С этой точки зрения способ гидротропной варки перспективен для получения технических целлюлоз с составом, удовлетворяющим получение определенных сортов бумаги. Поэтому задачей данного исследования является поиск оптимальных режимных параметров варки мискантуса для получения технической целлюлозы и оценка их использования для изготовления особых сортов бумаги.

\section{Материалы и методы}

В экспериментальном исследовании участвует Miscanthus sacchariflorus Andersson, выращенный на экспериментальной площадке ИПХЭТ СО РАН. Использовалась вся наземная часть растения, представленная стеблем с междоузлиями, листом и метелкой. Химический состав: массовая доля целлюлозы 52,1 \%; кислотонерастворимого лигнина - 18,6 \%; гемицеллюлоз 21,3 \%. Перед началом работы всю сухую массу измельчали до размера частиц 10-15 мм. Для варки готовилась суспензия из измельченного сырья и $35 \%$-го раствора бензоата натрия с модулем 1:10. Бензоат натрия (E211 CAS 532-32-1, поставщик A.M FOOD CHEMICAL CO., LIMITED Hebei Zhentian Food Addit Co., Ltd. Qingdao Twell Sansino Import \& Export Co., Tianjin Topglobal Co., Ltd.) - широко распространенная добавка к пище, консервант.

Обработка проводилась на универсальной термобарической установке периодического действия, состоящей из реакционной камеры с рабочим объемом 2,3 л [25], рассчитанной для проведения процесса под максимальным избыточным давлении 10,0 МПа и регулировкой температурного диапазона процесса 20-300 ${ }^{\circ} \mathrm{C}$. Процесс делигнификации мискантуса проводили при изменении режимных параметров варки. В качестве таких параметров были выбраны: температура в диапазоне $160-180^{\circ} \mathrm{C}$, продолжительность процесса 3,0-7,0 ч. По завершении варки реакционная камера охлаждалась до температуры $30-35{ }^{\circ} \mathrm{C}$, после чего реакционная масса выгружалась из аппарата. Твердый остаток реакционной массы (техническую целлюлозу) отделяли от отработанного варочного раствора путем механического прессования. Далее с целью предотвращения оседания лигнина на волокно целлюлозы ее промывали сначала свежей порцией $35 \%$-го раствора бензоата натрия при $90-95^{\circ} \mathrm{C}$ в течение 1 ч при слабом перемешивании (модуль 1:20) и проводили отжим целлюлозы от гидротропного раствора. Затем повторяли промывку с 20\%-м раствором бензоата натрия при тех же условиях. После отжима техническую целлюлозу промывали водой комнатной температуры до обесцвечивания промывных вод (3 промывки, модуль 1:25), отжимали и сушили на воздухе до влажности 7-10 \%.

Исследование химического состава мискантуса проводили по стандартным методикам [26]. Определение массовой доли целлюлозы по Кюршнеру основано на обработке целлюлозы спиртовым раствором азотной кислоты и количественном определении нерастворившегося 
остатка после промывки водой и высушивания. Определение массовой доли кислотонерастворимого лигнина базируется на количественном выделении лигнина гидролизом целлюлозы концентрированными минеральными кислотами (модификация Комарова). Определение массовой доли гемицеллюлоз основано на образовании фурфурола при обработке целлюлозы раствором с массовой долей соляной кислоты 13 \% при нагревании и выявлении отогнанного фурфурола спектрофотометрическим методом. Выход технической целлюлозы после варки рассчитывали на массу исходного образца по формуле

$$
n=\frac{m_{\text {вл }} \frac{(100-W)}{100}}{m_{\mathrm{M}}} \times 100 \%,
$$

где $n$ - выход технической целлюлозы, \%; $m_{\text {вл }}$ - масса технической целлюлозы, г; $m_{\mathrm{M}}-$ масса исходного образца мискантуса, г; $W$ - влажность технической целлюлозы, \%.

Работы, выполненные по гидротропной варке мискантуса и определению химического состава технической целлюлозы, проводили с использованием приборной базы Бийского регионального центра коллективного пользования СО РАН (ИПХЭТ СО РАН, г. Бийск).

Основные показатели механической прочности лабораторных образцов бумаги определяли в Инновационно-технологическом центре «Современные технологии переработки биоресурсов Севера» по разработанной в САФУ им. М.В. Ломоносова (г. Архангельск) методологии комплексной оценки характеристик качества целлюлозно-бумажных материалов на всех стадиях реального технологического процесса [27].

\section{Обсуждение результатов}

Оценку характеристик полученной при гидротропной варке целлюлозы осуществляли по нескольким основным показателям: выход и массовая доля лигнина и гемицеллюлоз в образцах. Исходное сырье неоднородно по морфологическому составу и содержит прочный стебель и мягкую листовую часть, что в процессе варки может приводить к появлению в технической целлюлозе включений непроваренного сырья, представленных твердыми частями растения - стеблями и междоузлиями. Поскольку такие включения оказывают заметное влияние на качество получаемой целлюлозы, то массу непроваренного сырья оценивали в каждом опыте.

План и результаты опытов по делигнификации мискантуса в термобарической установке типа $2^{3}$ представлены в табл. 1. При реализации опытов каждый из них был проделан трижды для того, чтобы оценить случайную погрешность эксперимента. В табл. 1 приведены усредненные данные по каждому из показателей технической целлюлозы.

По результатам математической обработки экспериментальных данных были построены экспериментально-статистические модели методом наименьших квадратов. Установлено, что выход технической целлюлозы, массовая доля лигнина и гемицеллюлоз в ней при варьировании температуры и продолжительности процесса описывают выражениями:

$$
\begin{aligned}
& Y=246,55-1,13 T-1,9167 t ; \\
& L=4,1331+0,0285 T-0,2425 t ; \\
& G=1036,125-11,5625 T-1,825 t+0,0325 T^{2}+0,0075 T t \\
& \quad-486-
\end{aligned}
$$


Таблица 1. План и результаты экспериментов по гидротропной варке мискантуса

Table 1. Experimental design and results for hydrotropic pulping of Miscanthus

\begin{tabular}{|c|c|c|c|c|c|c|}
\hline $\begin{array}{c}\text { № } \\
\text { опыта }\end{array}$ & $\begin{array}{c}\text { Температура, } \\
\text { оC }\end{array}$ & $\begin{array}{c}\text { Продолжитель- } \\
\text { ность варки, ч }\end{array}$ & $\begin{array}{c}\text { Выход } \\
\text { целлюлозы, \% }\end{array}$ & $\begin{array}{c}\text { Массовая } \\
\text { доля } \\
\text { лигнина, \% }\end{array}$ & $\begin{array}{c}\text { Массовая доля } \\
\text { гемицел- } \\
\text { люлоз, \% }\end{array}$ & $\begin{array}{c}\text { Массовая доля } \\
\text { непроварен- } \\
\text { ного сырья, \% }\end{array}$ \\
\hline 1 & 160 & 3 & 61,6 & 7,90 & 16,2 & 33,5 \\
2 & 160 & 5 & 55,3 & 7,47 & 15,0 & 16,8 \\
3 & 160 & 7 & 50,1 & 7,04 & 13,8 & 5,4 \\
4 & 170 & 3 & 48,7 & 8,30 & 8,2 & 2,4 \\
6 & 170 & 5 & 45,5 & 7,73 & 7,0 & 0,2 \\
7 & 170 & 7 & 43,4 & 7,33 & 5,8 & 0,1 \\
9 & 180 & 3 & 36,1 & 8,60 & 6,4 & 0,0 \\
\hline
\end{tabular}

где $Y$ - выход технической целлюлозы, \%; $L$ - массовая доля остаточного лигнина в образцах, \%; $G$ - массовая доля остаточных гемицеллюлоз в образцах, \%; $T$ - температура процесса, ${ }^{\circ} \mathrm{C} ; t-$ продолжительность процесса, ч.

Графическая интерпретация выражений (1) представлена на рис. 1a-в. Согласно выполненной экспериментально-статистической обработке все выражения подтвердили свою адекватность по критерию Фишера при уровне значимости 0,05 . Полуширина доверительных интервалов составила $\pm 2,42, \pm 1,23$ и $\pm 1,16$ соответственно для выхода технической целлюлозы, массовой доли остаточного лигнина и массовой доли остаточных гемицеллюлоз. В силу того, что разброс экспериментальных значений по массовой доле непроваренных частиц существенный и для нее невозможно подобрать какую-либо простейшую аппроксимационную зависимость, математическое описание данной функции выполнялось методом проекций (кусочная линейная аппроксимация). Результаты математического моделирования массовой доли непроваренных частиц в диапазоне температур $160-180{ }^{\circ} \mathrm{C}$ методом проекций представлены на рис. 12. По результатам видно, что, несмотря на высокий выход продукта, при проведении варки в диапазоне температурных значений $160-170{ }^{\circ} \mathrm{C}$ требуемая глубина обработки мискантуса не обеспечивается. Свидетельством этого является высокое содержание непроваренного сырья (свыше 3,5 \%) в образцах технической целлюлозы. Повышение температуры со 170 до $180{ }^{\circ} \mathrm{C}$ исключает долю непроваренного сырья в полученных образцах технической целлюлозы до минимума. После анализа данного показателя видим, что температурный режим обработки в диапазоне от 160 до $170{ }^{\circ} \mathrm{C}$ не следует рассматривать в качестве режима, обеспечивающего необходимое качество технической целлюлозы, поэтому дальнейший анализ полученных результатов будем проводить для температурного диапазона $170-180{ }^{\circ} \mathrm{C}$.

Выход технической целлюлозы, представленный на рис. $1 a$, снижается как при увеличении температуры варки, так и при увеличении продолжительности процесса. Это объясняется тем, что при гидротропной варке вследствие гидролиза происходит частичное разрушение целлюлозы и гемицеллюлоз, что наблюдается по результатам рис. 1в. Данный эффект известен и изучен, а результаты, представленные на рис. $1 a$, хорошо согласуются с результатами

$$
-487-
$$



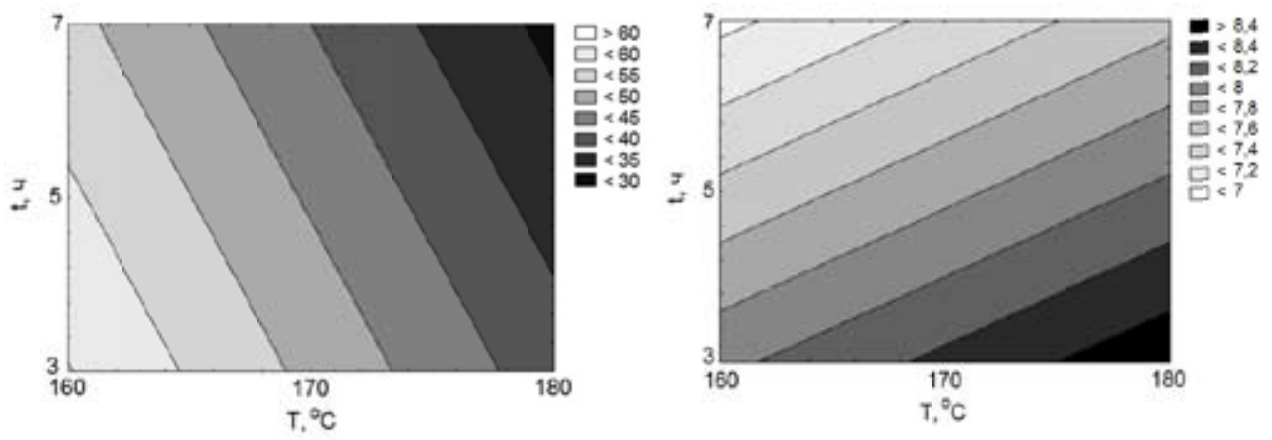

a

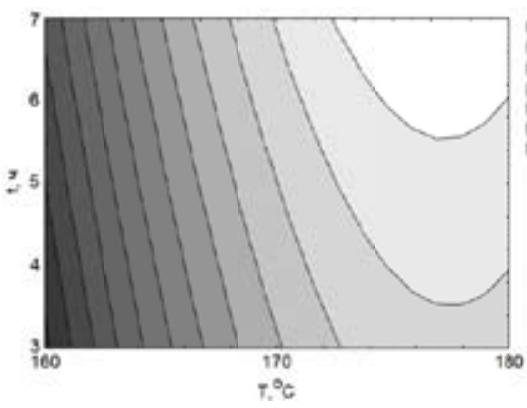

б

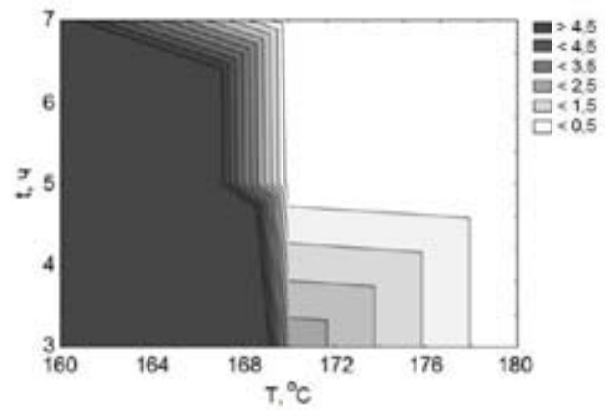

$\Gamma$

Рис. 1. Влияние условий обработки на выход и состав гидротропной целлюлозы: а - выход технической целлюлозы, \%; б-массовая доля остаточного лигнина, \%; в- массовая доля остаточных гемицеллюлоз, \%; г - массовая доля непроваренных частиц, \%

Fig. 1. Effect of treatment conditions on yield and chemical composition of hydrotropic pulp: a - Pulp yield, \%; $\mathrm{b}$ - content of residual lignin, $\%$; $\mathrm{c}$ - content of residual hemicelluloses, $\% ; \mathrm{d}$-content of uncooked particles, $\%$

работы [27]. Следует заметить, что при варке в условиях $170-180^{\circ} \mathrm{C}$ с увеличением продолжительности процесса выход продукта снижается почти в два раза. Гидротропная варка способствует уменьшению доли лигнина в технической целлюлозе в сравнении с исходным сырьем, однако при увеличении температуры и уменьшении продолжительности варки массовая доля лигнина в получаемой технической целлюлозе повышается вследствие более быстрого протекания процесса гидролиза целлюлозы и гемицеллюлозы. Продолжительность варки в отличие от температуры процесса оказывает менее заметное влияние на изменение массовой доли гемицеллюлоз. Остаточное количество гемицеллюлоз резко снижается с ростом температуры от 160 до $170{ }^{\circ} \mathrm{C}$, однако при дальнейшем увеличении температуры снижение количества гемицеллюлоз в образцах существенно не меняется. Таким образом, установлено, что проведение процесса при изменении температуры в диапазоне значений $170-180{ }^{\circ} \mathrm{C}$ и продолжительности варки 3-7 ч позволяет получать образцы целлюлозы с массовым содержанием гемицеллюлоз 5-11 \%. Такое количество гемицеллюлоз в продукте не оказывает негативного влияния при его дальнейшем использовании в качестве основы для бумаги, поскольку гемицеллюлозы способствуют повышению механической прочности, улучшают проклейку и размалываемость целлюлозы.

При поиске оптимальных условий проведения гидротропной варки мискантуса исходили из следующих соображений. Выход и массовая доля гемицеллюлоз должны стремиться к 
максимуму, а массовая доля лигнина в продукте должна быть минимальной. Основываясь на этих соображениях, в качестве параметра оптимизации нами был выбран обобщенный (среднеарифметический) параметр оптимизации Wa [28]. Весовыми функциями, входящими в данный параметр, являются безразмерные выход технической целлюлозы, массовые доли лигнина и гемицеллюлоз. В качестве ограничений, накладываемых на решение, рассматривали массовую долю непроваренных частиц, которая не должна превышать 0,5 \%. При вычислении среднеарифметического параметра оптимизации весовые коэффициенты у функций выхода технической целлюлозы, массовых долей лигнина и гемицеллюлоз составляли 0,4, 0,4 и 0,2 соответственно. Под оптимальными условиями варки понимают такие условия, при которых достигается максимум параметра оптимизации. Результаты решения задачи оптимизации (нахождения параметра оптимизации Wa) представлены на рис. 2.

На рис. 2 видно, что максимум параметра оптимизации в незаштрихованной зоне находится в точке, близкой к $\mathrm{T}=170{ }^{\circ} \mathrm{C} ; \mathrm{t}=7$ ч, которая соответствует оптимальным условиям проведения процесса гидротропной варки мискантуса.

С целью изучения возможности использования полученной гидротропным способом целлюлозы для изготовления бумаги были изготовлены лабораторные образцы с массой

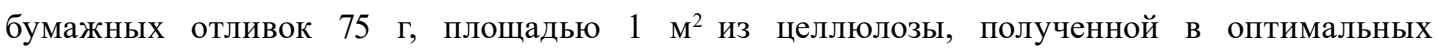
условиях при степени помола массы 60 ШР. Физико-механические показатели полученных образцов сравнивали со стандартами для сульфатной беленой целлюлозы из осины и смеси лиственных пород древесины, предназначенных для производства различных видов бумаги и картона, изготовляемых для нужд народного хозяйства и для экспорта. В табл. 2 приведены показатели качества бумаги из гидротропной технической целлюлозы, использовавшейся при изготовлении лабораторных образцов бумаги, в сравнении с показателями качества товарных марок сульфатной беленой целлюлозы первого сорта из лиственной древесины (осиновая) и сульфатной беленой целлюлозы из смеси лиственных пород древесины. Как следует из представленных результатов, изучаемый образец целлюлозы из мискантуса соответствует

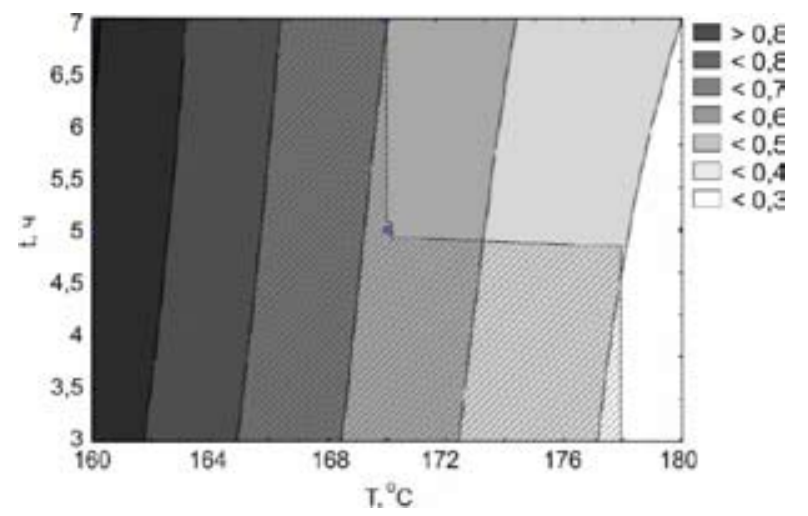

Рис. 2. Графическое представление поверхности отклика параметра оптимизации Wa в зависимости от режимных параметров процесса гидротропной варки

Fig. 2. Graphical representation of the response surface of optimization parameter Wa depending on hydrotropic pulping conditions 
Таблица 2. Показатели качества лабораторного образца бумаги из гидротропной целлюлозы мискантуса в сравнении с товарными марками целлюлоз из лиственных пород древесины

Table 2. Quality attributes of the lab-scale paper specimen produced from hydrotropic Miscanthus pulp as compared to brand pulps from hardwoods

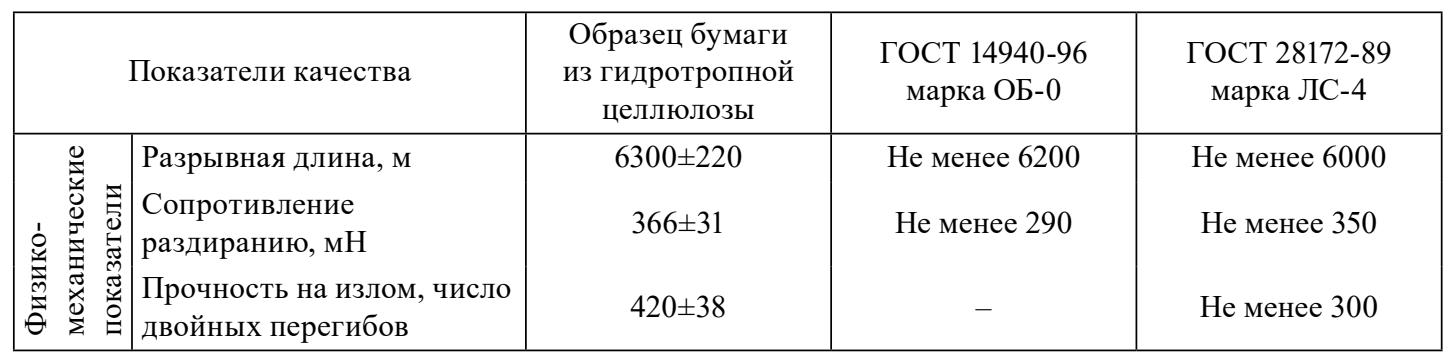

товарным маркам ОБ-0 и ЛС-4 для лиственных пород. Помимо основных показателей качества определены показатели, характеризующие эксплуатационные характеристики полученных образцов. Установлено, что лабораторные образцы из целлюлозы мискантуса характеризуются сопротивлением к продавливанию в узком диапазоне $86 \ldots 90$ кПа, длиной волокна гидротропной целлюлозы 0,667 мм. Также они обладают удовлетворительными значениями жесткости при растяжении 315 кН/м, разрушающего напряжения 17 МПа и разрушающей деформации 1,23 \%. Таким образом, полученные образцы целлюлозы из мискантуса гидротропным способом могут успешно применяться в качестве альтернативного сырья для производства соответствующих видов бумаги и картона.

\section{Выводы}

Исследовано влияние режимных параметров гидротропной варки мискантуса на выход, массовые доли лигнина, гемицеллюлоз и частиц непроваренного сырья при варьировании температуры и продолжительности варки в диапазонах $160-180{ }^{\circ} \mathrm{C}$ и 3-7 ч соответственно. Установлены математические выражения, описывающие значения данных характеристик внутри исследованного диапазона режимных параметров. Показано, что при гидротропной варке мискантуса при температурах $160-170{ }^{\circ} \mathrm{C}$ не обеспечивается необходимое качество обработки, так как в полученной целлюлозе присутствует значительная доля непроваренного сырья. На основе полученных математических выражений определены оптимальные условия гидротропной варки, соответствующие максимуму обобщенного параметра оптимизации Wa. Установлено, что для получения качественной технической целлюлозы с максимальным выходом данного продукта необходимо осуществлять процесс варки при температуре $170{ }^{\circ} \mathrm{C}$ и длительности 7 ч. Выполнена оценка возможностей применения полученной технической целлюлозы в качестве основы для бумаги. Показано, что образцы бумаги, полученные гидротропной варкой мискантуса в оптимальных условиях, соответствуют по характеристикам товарным маркам целлюлоз ОБ-0 и ЛС-4 из лиственных пород. Таким образом, результаты данного исследования подтверждают перспективность использования мискантуса в качестве альтернативного источника сырья для изготовления бумажных изделий и картона. 


\section{Благодарность / Acknowledgement}

Исследование выполнено по проекту в рамках Государственной программы с регистрационным номером темы АААА-A17-117011910006-5.

The study was conducted under the State Assignment Program with Theme Registration No. AAAA-A17-117011910006-5.

\section{Список литературы}

1. Rodríguez A., Moral A., Serrano L., Labidi J., Jiménez L. Use of high-boiling point organic solvents for pulping oil palm empty fruit bunches. Bioresource Technology 2008. Vol. 99(8), P. 17431749 .

2. Sharma N., Godiyal R.D., Bhawana, Thapliyal B.P., Kumar. Anupam Pulping and Bleaching of Hydro Distillation Waste of Citronella Grass (Cymbopogon winterianus Jowitt) for Papermaking. Waste and Biomass Valorization 2018. Vol. 9(3), P. 409-419.

3. Запасов древесины в Сибири при существующей системе заготовки хватит на 15 лет эксперт [Электронный ресурс]. Режим доступа:http://www.interfax-russia.ru/Siberia/news. asp?id $=1021986 \&$ sec $=1671$ [Timber reserves in Siberia with the existing procurement system will last for 15 years - expert [Electronic resource]. Access mode:http://www.interfax-russia.ru/Siberia/ news.asp?id $=1021986 \&$ sec $=1671$ (In Russ.) $]$

4. Singh P., Sulaiman O., Hashim R., Leh Cheu Peng, Singh R.P. Using biomass residues from oil palm industry as a raw material for pulp and paper industry: potential benefits and threat to the environment. Environment. Development and Sustainability 2013. Vol. 15(3), P. 367-383.

5. Пен Р.3., Казаков Я.В., Каретникова Н.В., Вшивкова И.А. Свойства пероксидной целлюлозы из однолетних растений. 5. Деформационные свойства листа. Химия растительного сырья 2013. № 3, C. 65-69 [Pen R.Z., Kazakov I.V., Karetnikova N.V., Vshivkova I.A. Properties of peroxide cellulose from annual plants. 5. Deformation properties of the sheet. Chemistry of plant raw materials 2013. No 3, P. 65-69. (In Russ.)]

6. Pydimalla M., Muthyala B.R., Adusumalli R.B. Influence of Temperature on Kraft Pulping of Whole Bagasse and Depithed Bagasse. Sugar Tech 26 March 2019, P. 1-13.

7. Левданский В.А., Левданский А.В., Кузнецов Б.Н. Способ получения из льна целлюлозного продукта с высоким содержанием альфа-целлюлозы. Журнал Сибирского федерального университета. Серия: Химия 2014. Т. 7(1), C. 63-70. [Levdansky V.A., Levdansky A.V., Kuznetsov B.N. The method of obtaining from flax pulp product with a high content of alpha-cellulose. Journal of Siberian Federal University. Chemistry 2014. Vol. 7(1), P. 63-70.(In Russ.)]

8. Дорогина О.В., Васильева О.Ю., Нуждина Н.С., Буглова Л.В., Гисматулина Ю.А., Жмудь Е.В., Зуева Г.А., Комина О.В., Цыбченко Е.А. Ресурсный потенциал некоторых видов рода Miscanthus Anderss. в условиях континентального климата лесостепи Западной Сибири. Вавиловский журнал генетики и селекции 2018. Т. 22(5), C. 553-559. [Dorogina O.V., Vasilyeva O.Yu., Nuzhdina N.S., Buglova L.V., Gismatulina Yu.A., Zhmud E.V., Zueva G.A., Komina O.V., Tsybchenko E.A. Resource potential of some species of the genus Miscanthus Anderss. in terms of the continental climate of the forest-steppe of Western Siberia. Vavilov Journal of Genetics and Breeding 2018. Vol. 22(5), P. 553-559. (In Russ.)] 
9. Danielewicz D., Dybka-Stępień K., Surma-Ślusarska B. Processing of Miscanthus giganteus stalks into various soda and kraft pulps. Part I: Chemical composition, types of cells and pulping effects. Cellulose 2018. Vol. 25(11), P. 6731-6744.

10. Burner D.M., Hale A.L., Carver P., Pote D.H., Fritschi F.B. Biomass yield comparisons of giant Miscanthus, giant reed, and miscane grown under irrigated and rained conditions. Industrial Crops and Products 2015. Vol. 76, P. 1025-1032.

11. Gismatulina Y.A., Budaeva V.V. Chemical composition of five Miscanthus sinensis harvests and nitric-acid cellulose therefrom. Industrial Crops and Products 2017. Vol. 109, P. 227-232.

12. Brosse N., Dufour A., Meng X., Sun Q., Ragauskas A. Miscanthus: a fast-growing crop for biofuels and chemical production. Biofuels, Bioproducts and Biorefining 2012. Vol. 6(5), P. 1-17.

13. Danielewicz D., Surma-Slusarska B., Zurek G., Martyniak D., Kmiotek M., Dybka K.Selected grass plants as biomass fuels and raw materials for papermaking. Part II: pulp and paper properties. BioResources 2015b. Vol. 10(4), P. 8552-8564.

14. Marin F., Sanchez J.L., Aruzo J., Fuertes R., Gonzalo A. Semichemical pulping of Miscanthus giganteus. Effect of pulping conditions on some pulp and paper properties. Bioresource Technology 2009. Vol. 100(17), P. 3933-3940.

15. Cappelletto P., Mongardini F., Barberi B., Sannibale M., Brizzi M., Pignatelli V. Papermaking pulps from the fibrous fraction of Miscanthus giganteus. Industrial Crops and Products 2000. Vol. 11(2-3), P. 205-210.

16. Vena P.F., Brienzo M., Garcia-Aparicio M.P., Goergens J.F., Rypstra T. Hemicelluloses extraction from giant bamboo (Bambusa balcooa Roxburgh) prior to kraft or soda-AQ pulping and its effect on pulp physical properties. Holzforschung 2013. Vol. 67(8), P. 863-870.

17. Geng W., Narron R., Jiang X., Pawlak J. J., Chang Hou-min, Park S., Jameel H., Venditti R.A.The influence of lignin content and structure on hemicellulose alkaline extraction for non-wood and hardwood lignocellulosic biomass. Cellulose 2019. Vol. 26(5), P. 3219-3230.

18. Razali N., Ong P., Ibrahim M., Wan Daud W.R., Zainuddin Z. Modeling of acetosolv pulping of oil palm fronds using response surface methodology and wavelet neural networks. Cellulose 2019. Vol. 26(7), P. 4615-4628.

19. Zhao J., Li X.Z., Qu Y.B., Gao P.J. Alkaline peroxide mechanical pulping of wheat straw with enzyme treatment. Applied Biochemistry and Biotechnology 2004. Vol. 112(1), P. 13-23.

20. Dedhia B.S., Csoka L., Rathod V.K.Xylanase and Ultrasound Assisted Pulping of Wheat Straw. Applied Biochemistry and Biotechnology 2012. Vol. 168(4), P. 731-741.

21. Denisova M.N., Budaeva V.V., Pavlov I.N. Pulps isolated from miscanthus, oat hulls, and intermediate flax straw with sodium benzoate. Korean Journal of Chemical Engineering 2015. Vol. 32, P. 202-205.

22. Molin U., Teder A. Importance of cellulose/hemicellulose-ratio for pulp strength. Nordic Pulp and Paper Research Journal 2002. Vol. 17(1), P. 14-20.

23. Schönberg C., Oksanen T., Suurnäkki A., Kettunen H., Buchert J. The importance of xylan for the strength properties of spruce kraft pulp fibres. Holzforschung 2001. Vol. 55(6), P. 639-645.

24. Iwamoto S., Abe K., Yano H. The effect of hemicelluloses on wood pulp nanofibrillation and nanofiber network characteristics. Biomacromolecules 2008. Vol. 9(3), P. 1022-1028. 
25. Pavlov I.N., Denisova M.N., Makarova E.I., Budaeva V.V., Sakovich G.V. Versatile thermobaric setup and production of hydrotropic cellulose therein. Cellulose Chemistry and Technology 2015. Vol. 49(9-10), Р. 847-852.

26. Оболенская А.В., Ельницкая 3.П., Леонович А.А. Лабораторные работы по химии древесины и целлюлозы. М.: Экология, 1991. 320 с. [ObolenskayaA.V., El’nickayaZ.P., Leonovich A.A. Laboratory work on the chemistry of wood and cellulose. Moscow, Ecology, 1991, 320 p. (In Russ.)]

27. Гисматулина Ю.А., Севастьянова Ю.В., Будаева В.В., Золотухин В.Н. Структурноразмерные характеристики целлюлозы из мискантуса. Фундаментальные исследования 2015. № 2, C. 3523-3526.[Gismatulina Yu.A., Sevastyanova Yu.V., Budaeva V.V., Zolotukhin V.N. Structural and dimensional characteristics of miscanthus cellulose. Fundamental research 2015. No 2, P. 35233526. (In Russ.)]

28. Пен Р.З. Статистические методы моделирования и оптимизации процессов целлюлознобумажного производства. Красноярск: Изд-во КГУ, 1982. 192 с. [Pen R.Z. Statistical methods for modeling and optimization of pulp and paper production processes: Proc. allowance. Krasnoyarsk, Publishing house KSU, 1982. 192 p. (In Russ.)] 